\title{
Students' Perceptions of Emotional and Instrumental Teacher Support: Relations with Motivational and Emotional Responses
}

\author{
Roger A. Federici ${ }^{1} \&$ Einar M. Skaalvik ${ }^{1}$ \\ ${ }^{1}$ Department of Education, Norwegian University of Science and Technology, Trondheim, Norway \\ Correspondence: Roger A. Federici, Department of Education, Norwegian University of Science and Technology, \\ 7491 Trondheim, Norway. Tel: 47-9593-6231. E-mail: roger.federici@ntnu.no
}

Received: November 7, 2013

doi:10.5539/ies.v7n1p21
Accepted: December 8, 2013 Online Published: December 15, 2013

URL: http://dx.doi.org/10.5539/ies.v7n1p21

\begin{abstract}
We explored whether students' perceptions of emotional and instrumental support provided by their mathematics teacher constitute separate dimensions of teacher support and how they are related. We also analyzed how students' perceptions of emotional and instrumental support in math lessons relate to math anxiety, intrinsic motivation, help-seeking behavior, and effort. The participants were 309 Norwegian students in 9th and 10th grade. The data were analyzed by means of structural equation modeling (SEM). The results revealed that emotional and instrumental support constitute separate but strongly correlated constructs. Directly or indirectly, both emotional and instrumental support was related to all motivational constructs. The strongest relations were found for instrumental support. Additionally, instrumental support predicted lower levels of anxiety. One implication of this study is that teachers should aim at providing both emotional and instrumental support.
\end{abstract}

Keywords: teacher support, anxiety, intrinsic motivation, help-seeking behavior, effort

\section{Introduction}

Research investigating motivational dynamics in schools often focuses on individual differences in students' underlying beliefs and capacities, such as academic self-concept, self-efficacy, goals, and values (Furrer \& Skinner, 2003). Researchers also note the centrality of social factors in students' motivation (e.g., Deci \& Ryan, 2000; Furrer \& Skinner, 2003; Goldstein, 1999; Jang, Reeve, \& Deci, 2010; Katz, Kaplan, \& Gueta, 2010; Wentzel, Battle, Russell, \& Looney, 2010). In particular, researchers are concerned with the quality of the teacher-student relationship and how it relates to different measures of motivation for schoolwork. A number of studies provide strong evidence that a positive teacher-student relationship is predictive of student engagement and motivation, effort, adaptive learning strategies, student achievement and student well-being (e.g., Furrer \& Skinner, 2003; Hamre \& Pianta, 2001; Marchand \& Skinner, 2007; Niehaus, Rudasill, \& Rakes, 2012; Pianta, Hamre, \& Stuhlman, 2003; Sakiz, Pape, \& Hoy, 2012; Wentzel, 1999).

The purpose of the present study was to explore relations between students' perception of teacher support and different motivational and emotional responses. Research identifies several dimensions of teacher support, such as emotional, informational, appraisal, and instrumental support (e.g., House, 1981; Malecki \& Demaray, 2003). The number of dimensions and the labels used for them varies. However, in general, the two categories of emotional and instrumental support are typically reported (Semmer et al., 2008). Emotional support is characterized by empathy, friendliness, encouragement, esteem, and caring, whereas instrumental support is characterized by tangible support, for instance, when teachers help students solve a problem or accomplish a difficult task (Semmer et al., 2008). The present study first tests whether students' perceptions of emotional and instrumental support provided by their mathematics teachers constitute separate dimensions of teacher support and how strongly they are related. Secondly, we explore how students' perceptions of emotional and instrumental support in mathematics relate to math anxiety, intrinsic motivation, help-seeking behavior, and effort.

\section{Theoretical Perspectives}

\subsection{Emotional Support}

Definitions of emotional support typically include students' perceptions of trust, warmth, respect, and love as well as communications of empathy and care from their teachers (e.g., Langford, Bowsher, Maloney, \& Lillis, 
1997; Patrick, Kaplan, \& Ryan, 2011). Theoretically, one may distinguish between general and specific emotional support. General emotional support refers to students' general perception of the teachers or of a particular teacher as warm, friendly, encouraging, and accepting that students have different abilities. Specific emotional support refers to emotional support in particular situations, for instance, when a student is working on a difficult task or worry about not having friends in school. An inspection of the measures of emotional support in the research literature reveals that the construct has almost entirely been measured as students' general perception of the teachers as warm and friendly (e.g., De Wit, Karioja, Rye, \& Shain, 2011; Wentzel et al., 2010).

Students' perception of emotional support is related to their feeling of belonging, relatedness or connectedness (e.g., Marchand \& Skinner, 2007). For instance, Furrer and Skinner (2003) measured students' sense of belonging and relatedness using items that assessed their feeling of being accepted and appreciated by the teachers. Such measures differ from other measures of social support in that they do not ask students about teacher characteristics (e.g., being friendly) or what teachers do (e.g., care about students). Rather, they evaluate how students feel when they are with their teachers.

Although students' perception of emotional support and feeling of relatedness may be conceptualized as different constructs, one may assume that they are related. Theoretically, one may perceive belonging, relatedness, and safety as consequences of emotional support, whereas lack of emotional support in an achievement context may result in lower levels of belonging and higher levels of anxiety. The resultant feeling of belonging, relatedness, and safety may partially explain the impact of emotional support on students' motivation and well-being. For instance, Baumeister and Leary (1995) assert that feeling of belonging is a fundamental need and that all individuals are inherently motivated to connect with others and form social bonds. They emphasizes that negative outcomes (e.g., psychological distress) may occur when individuals are not socially connected, providing support for the argument that feeling of belonging is not only desired, but needed (Baumeister \& Leary, 1995; Niehaus et al., 2012). Similarly, educational researchers within the self-determination perspective emphasize the importance of students' feeling of connectedness to school (e.g., Deci \& Ryan, 2000; Ryan \& Deci, 2000, 2006). According to Martin and Dowson (2009), relatedness provides the required emotional security that individuals need to actively explore and effectively address their worlds.

Findings consistently indicate that positive perceptions of teachers as emotionally supportive are associated with positive educational outcomes. For instance, previous research reveals positive associations with students' engagement (Patrick, Ryan, \& Kaplan, 2007), academic initiative (Danielsen, Wiium, Wilhelmsen, \& Wold, 2010), intrinsic motivation (E. Skaalvik \& S. Skaalvik, 2013; Wentzel et al., 2010), and higher self-esteem and lower levels of anxiety (De Wit et al., 2011). Moreover, students who feel emotionally supported are more likely to expend effort (Goodenow \& Grady, 1993; Wentzel, 1994), ask for help (Newman \& Schwager, 1993), and use self-regulated learning strategies (Ryan \& Patrick, 2001). Studies of belonging and relatedness also show positive associations with students' engagement (Furrer \& Skinner, 2003) and help-seeking behavior (Marchand \& Skinner (2007). Moreover, research indicates that students who perceive a positive school environment and share positive relationships with their teachers tend to have higher grades (Crosnoe, Johnson, \& Elder, 2004; Roeser, Midgley, \& Urdan, 1996).

Based on theory and previous research, we expected perceived emotional support in mathematics lessons to be positively related to measures of motivation for mathematics and negatively related to math anxiety. An interesting question was whether the relations between emotional support and measures of motivation were, at least partially, mediated by lower levels of anxiety.

\subsection{Instrumental Support}

Whereas emotional support is characterized by students' perceptions of trust, warmth, respect, and care, instrumental aspects are characterized by tangible support. One may therefore, refer to nurturing versus action-facilitating support (Cutrona \& Suhr, 1994; Semmer et al., 2008). Definitions of instrumental support typically include students' perceptions of being provided with instrumental resources and practical help (Malecki \& Demaray, 2003; Suldo et al., 2009). This may include teachers' questioning, clarifying, correcting, elaborating, and modeling behaviors that contribute to understanding, problem solving or skill development (Malecki \& Demaray, 2003). Such practical support is noted in various motivational theories, for instance, Bandura's social cognitive theory, which highlights the essential role of communication and modeling in promoting mastery experiences and expectations, which again increases motivation and performance outcomes and decreases anxiety (Bandura, 1977, 1997).

Empirical studies indicate that students' perceptions of instrumental support have consequences for their 
motivation and functioning. For instance, a study of Suldo et al. (2009) investigated which types of perceived social support were most strongly associated with middle school students' subjective well-being. Instrumental support was measured as the students' perception of tangible support (e.g., "Teachers take time to help me learn to do something well."). Regression analysis indicated that instrumental support predicted students' subjective well-being $(\beta=.19)$. However, the evidence is mixed. For instance, Malecki and Demaray (2003) investigated the types of support that students most often perceived from different sources and the degree to which different types of support were related to students' social, behavioral, and academic outcomes. These researchers found that emotional, but not instrumental support was significantly related to academic outcomes.

Despite the emphasis on instrumental support in motivational theories, a literature search indicates that empirical studies of students' perception of instrumental support are not as prominent as those examining emotional support. Moreover, there is mixed evidence regarding instrumental support and student outcomes. Also, there is a lack of consistency in the terminology used (e.g., instrumental or instructional support). According to Malecki and Demaray (2003), much of the empirical evidence regarding the positive outcomes of teacher support has been based on either global measures of teacher support or on measures emotional support (Malecki \& Demaray, 2003). Despite the lack of empirical research, we expected instrumental support to be positively related to motivational constructs and negatively related to anxiety. Our expectations were based on social cognitive theory. From this perspective instrumental support increases mastery experience that is the most important source of mastery expectations or self-efficacy. In turn, self-efficacy increases motivation and motivated behavior and decreases anxiety.

\subsection{Motivational and Emotional Responses}

Four motivational and emotional constructs are included in the current study, namely, math anxiety, intrinsic motivation for mathematics, help-seeking behavior in math lessons, and effort when working with mathematics. We perceive math anxiety as a general state anxiety. State anxiety is an emotional response that occurs occasionally, manifests itself in specific situations, has a relatively short duration, varies in intensity, and involves physiological reactions (Spielberger, 1972, 1979). In school it often occurs in test situations but can also manifest itself as a general anxiety when working with a particular subject, for instance mathematics. When students perceive their teachers as supportive, they are more likely to be interested in academic activities and less likely to be anxious (Baumeister \& Leary, 1995; Wentzel, 1998; Yildirim, 2012). For instance, a study of Ahmed et al. (2010) revealed that perceived teacher support positively predicted students' interest and enjoyment but negatively predicted anxiety in mathematics. Also, the finding that anxiety is a significant negative predictor of learning strategy and achievement in mathematics is robust (e.g., Lapointe, Legault, \& Batiste, 2005; Metallidou \& Vlachou, 2007). These findings indicate that students' math anxiety may be influenced by the degree of teacher support that they receive.

Intrinsic motivation may be defined as the inherent pleasure and satisfaction derived from engaging in an activity (Deci \& Ryan, 1985). Previous studies reveal that boys show higher intrinsic motivation for mathematics than girls (Bezzina, 2010; S. Skaalvik \& E. Skaalvik, 2004) and that intrinsic motivation is positively related to effort, help-seeking behavior, and performance and negatively related to state anxiety (e.g., Cecchini et al., 2001; Marchand \& Skinner, 2007; S. Skaalvik \& E. Skaalvik, 2004; Yildirim, 2012). A useful framework for understanding why students are intrinsically motivated in a particular domain, such as mathematics, is self-determination theory (Deci \& Ryan, 1985, 2000; Ryan \& Deci, 2000). The main postulate of the theory is that social factors promote intrinsic motivation via satisfaction of individuals' fundamental needs for autonomy, competence, and relatedness (Deci \& Ryan, 2000). Teachers may stimulate these needs in a variety of ways. For instance, teachers' emotional support may stimulate the students' need for relatedness, thus increasing their intrinsic motivation. Moreover, teachers' instrumental support may stimulate both the need for competence and autonomy. Thus, we expected both emotional and instrumental support to predict intrinsic motivation, both directly and indirectly through reduced math anxiety.

Help-seeking is a behavioral self-regulatory strategy that includes cognitive, motivational, affective, and social aspects (Sakiz, 2012). Given optimal challenge in school, all students will encounter difficulty in their work with mathematics and need guidance and feedback. Therefore, help-seeking complements the value of instruction (Karabenick, 2004; Karabenick \& Sharma, 1994) and is an important self-regulatory strategy that contributes to student learning (e.g., Newman, 1998, 2000; Ryan, Gheen, \& Midgley, 1998). Nelson-LeGall and Resnick (1998) maintain that help-seeking not only holds the potential of working through an immediate academic difficulty but also contributes to the acquisition of skills and knowledge that can be used in subsequent learning situations. By contrast, the avoidance of seeking help when it is needed is counter-productive. It may result in misunderstandings, lack of problem solving, and lack of important skills (Ryan et al., 1998; Searcy \& Eisenberg, 
1992).

According to Karabenick (2004), the process of seeking help is inherently social; therefore, features of the learning context are especially relevant. One of the most direct social influences is the perceived receptivity of teachers to requests for assistance, and how teachers respond is an essential determinant of whether students seek help (Karabenick, 2004; Newman \& Goldin, 1990). The research literature supports the notion that teacher support promotes students' help-seeking. For instance, teacher behaviors such as caring, listening and showing concern for students increase students' tendency to seek academic help, especially in elementary and middle school classrooms (e.g., Newman, 2002, 2008; Ryan et al., 1998). Moreover, Myers, Edwards, Wahl, and Martin (2007) found that instructor aggressive communication behaviors were negatively related to college students' willingness to ask questions, overt information seeking and engagement. Thus, we expect both emotional and instrumental teacher support to predict students' help-seeking behavior.

We also expected teacher support to be positively related to students' effort, both directly and indirectly through intrinsic motivation (Sakiz et al., 2012). For instance, students who are motivated to learn should be willing to expend effort to succeed (Pintrich \& Schunk, 2008). Moreover, teachers who provide both emotional and instrumental support likely make students feel that they are valued and respected, which in turn improves effort, academic values, and achievement. Especially for instrumental support, social cognitive theory notes that people who are socially persuaded to believe in their ability exert greater effort on tasks than those who are not convinced about their ability to master difficult situations (Bandura, 1977, 1997). Positive perceptions of emotional and instrumental support should therefore lead to increased effort.

\section{Purpose of the Study and a Theoretical Model}

One purpose of the present study was to test whether students' perceptions of the emotional and instrumental support provided by their mathematics teacher constitute separate dimensions of teacher support and how strongly they are related. Another purpose was to test a theoretical model of relations between the two anticipated dimensions of teacher support and math anxiety, intrinsic motivation, effort, and help-seeking behavior (Model 1, see Figure 1).

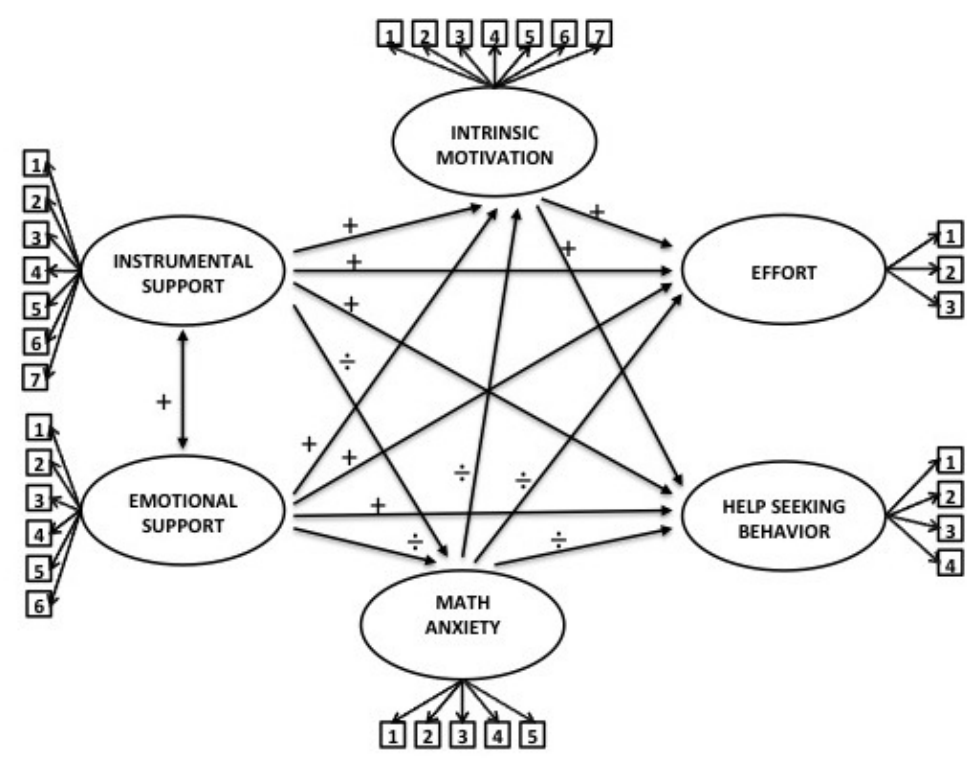

Figure 1. Theoretical model of relations between the constructs

The theoretical model is based on the analyses and predictions presented above (see "Theoretical perspectives"). Both emotional and instrumental support provided by the math teachers were expected to be negatively related to math anxiety. Moreover, both dimensions of teacher support were expected to be positively related to intrinsic motivation, effort, and help-seeking behavior in mathematics, both directly and indirectly through math anxiety. Furthermore, we expected intrinsic motivation to be positively related to effort and help-seeking behavior. 


\section{Method}

\subsection{Participants and Procedure}

Participants in the present study were students from two middle schools $\left(8^{\text {th }}-10^{\text {th }}\right.$ grade) located in one of the large cities in Norway. A total of 309 students in ninth $(34 \%)$ and tenth $(66 \%)$ grade responded to the survey. The sample consisted of $48.2 \%$ males and $51.8 \%$ females. The data were collected by means of a questionnaire that was administered in the school classes by a research assistant.

\subsection{Instruments}

The instruments in the present study were developed and administered in Norwegian. The items represent translations into English. The response categories for all items except grades were provided on a 6-point scale ranging from "Absolutely disagree" (1) to "Absolutely agree" (6). A 6-point scale is often used at the middle school and high school level, for example the Self Description Questionnaire (Marsh, 1990).

Students' perceptions of the teachers as emotionally supportive were measured by six items. The scale is an extended and modified version of a previously tested scale of emotional support (E. Skaalvik \& S. Skaalvik, 2013). Examples of items are as follows: "I feel that my math teacher cares about me", "I feel that my math teacher is friendly", and "My math teacher makes me feel safe". These items indirectly tap into students' feeling of being liked, respected, and valued by the mathematics teacher, which Goodenow (1993) recognizes as important requirements of belonging. Thus, the scale may also be regarded as an indicator of the emotional dimension of the teacher-student relationship as experienced by the students. Cronbach's alpha for the scale was .94 .

Instrumental support was measured by a seven-item scale that was developed for the purpose of the present study. The scale focused on the students' perceived instrumental support from their math teacher. Examples of items are as follows: "When there is something I do not understand in mathematics, my math teacher explains it well for me", "When I have problems with math, I get good help and guidance from my math teacher", and "My math teacher helps me so that I understand the math problems". Cronbach's alpha for the scale was .95.

Intrinsic motivation was defined as interest in working with or liking to work with mathematics. It was measured by a six-item scale. Examples of items are as follows: "I like mathematics" and "Working with mathematics is fun". The scale had a Cronbach's alpha of 0.93 .

Math anxiety was measured by a five-item math anxiety scale with a Cronbach's alpha of .87 . The scale focuses on the emotionality dimension of anxiety. Examples of items in the scale are as follows: "I am tense in mathematics lessons", and "I am nervous in mathematics lessons".

Help-seeking behavior was measured by four items. The items were derived from a previously tested scale for help-seeking behavior in mathematics (S. Skaalvik \& E. Skaalvik, 2005). Examples of items are as follows: "If there is something I do not understand in math, I ask the teacher for help", "If I am working on a math problem that I am not able to solve, I ask the teacher for advice", and "In mathematics lessons, I do not ask for help even if I do not understand the problem I am working with". Cronbach's alpha for the scale was .83.

Effort was conceptualized as individual students' feelings of working hard, doing their homework, and putting in their best effort. It was measured by three items that represent a modified version of a previously tested scale (E. Skaalvik \& S. Skaalvik, 2013). The items were as follows: "I always do my best when I am working with mathematics", "I always do my homework in mathematics", and "I often rush through my work in mathematics". Cronbach's alpha for the scale was .77.

The students' level of achievement in mathematics was indicated by their grades in the previous semester. Grades in Norwegian schools are given on a six-point scale ranging from 1-6, with the latter indicating the highest possible grade.

\subsection{Data Analysis}

The data were analyzed by means of confirmatory factor analysis (CFA) and structural equation modeling (SEM) using the AMOS 20 program. We first tested two measurement models by means of CFA. The first model defined emotional and instrumental support as separate but correlated constructs, whereas the second model defined math anxiety, intrinsic motivation, effort, and help-seeking behavior as separate and correlated constructs. Secondly, we explored relations between the variables by means of structural equation modeling (SEM). SEM is a statistical methodology that takes a confirmatory approach to the analysis (Byrne, 2010). In this approach, a hypothesized model of relations between the constructs is tested statistically to determine the extent to which it is consistent with the data, which is referred to as the goodness of fit. If the goodness of fit is 
adequate, the plausibility of the relations among the constructs is supported. To assess the model fit, we used well-established indices such as CFI, IFI, TLI, and RMSEA as well as chi-square test statistics. For the CFI, IFI, and TLI indices, values greater than .90 are typically considered acceptable and values greater than .95 indicate a good fit to the data (Byrne, 2010; Hu \& Bentler, 1999). For well-specified models, a RMSEA of .06 or less reflects a good fit (Hu \& Bentler, 1999; Tabachnick \& Fidell, 2007).

\section{Results}

\subsection{Correlations and Descriptive Statistics}

Table 1 shows correlations between the study variables and maximum possible scores, statistical means, standard deviations, and Cronbach's alphas. Boys had higher intrinsic motivation for mathematics than girls. Grades or level of performance in mathematics were negatively related to math anxiety and positively related to perceived teacher support and to the motivational constructs. Students' perceptions of emotional and instrumental support were strongly correlated $(r .=.80)$. The three motivational variables, intrinsic motivation, effort, and help-seeking behavior, were moderately correlated (between .38 and .41). Math anxiety was not significantly related to effort but was significantly and negatively related to all other variables in the study. Both emotional and instrumental support were positively related to intrinsic motivation, effort, and help-seeking behavior.

Table 1. Zero order correlations and descriptive statistics of the study variables

\begin{tabular}{lcccccccc}
\hline \multicolumn{1}{c}{ Variable } & 1 & 2 & 3 & 4 & 5 & 6 & 7 & 8 \\
\hline 1. Gender & - & & & & & & & \\
2. Grades in mathematics & .057 & - & & & & & & \\
3. Emotional support & .032 & $.204^{* *}$ & - & & & & & \\
4. Instrumental support & .097 & $.233^{* *}$ & $.796^{* *}$ & - & & & & \\
5. Intrinsic motivation & $.186^{* *}$ & $.506^{* *}$ & $.294^{* *}$ & $.415^{* *}$ & - & & & \\
6. Math anxiety & -.106 & $-.302^{* *}$ & $-.136^{*}$ & $-.131^{*}$ & $-.323^{* *}$ & - & & \\
7. Help-seeking behavior & -.085 & $.305^{* *}$ & $.253^{* *}$ & $.323^{* *}$ & $.377^{* *}$ & $-.332^{* *}$ & - & \\
8. Effort & -.105 & $.344^{* *}$ & $.234^{* *}$ & $.303^{* *}$ & $.412^{* *}$ & -.071 & $.384^{* *}$ & - \\
\hline Maximum possible score & 2 & 6 & 36 & 42 & 36 & 30 & 24 & 18 \\
Number of items & 1 & 1 & 6 & 7 & 6 & 5 & 4 & 3 \\
Mean & - & 4.05 & 28.55 & 31.54 & 19.59 & 10.95 & 18.33 & 12.92 \\
Skewness & - & -0.27 & -1.15 & -1.04 & -0.04 & 0.98 & -0.95 & -0.61 \\
Standard deviation & - & 1.17 & 7.23 & 8.65 & 8.62 & 6.46 & 5.11 & 3.67 \\
Cronbach's alpha & - & - & .94 & .95 & .93 & .87 & .83 & .77 \\
\hline
\end{tabular}

Note: ${ }^{*} \mathrm{p}<.05,{ }^{* *} \mathrm{p}<.01$. The estimates are based on observed data. Females are coded 1 and males are coded 2.

\subsection{Measurement Models}

The factor structure of teacher support was investigated by testing two measurement models by means of confirmatory factor analyses. The first model consisted of one primary factor with loadings on all 13 observed items. Based on the strong correlation between emotional and instrumental support, this model was tested to ascertain whether teacher support could be treated as a one-dimensional construct. The second defined two correlated primary factors corresponding to the two theoretical dimensions. None of the error variances in the models were allowed to correlate. The first model did not fit the data well $(\chi 2(65, N=309)=624.63, p<.001$, $\mathrm{CMIN} / \mathrm{DF}=9.610, \mathrm{RMSEA}=0.167, \mathrm{IFI}=0.869, \mathrm{TLI}=0.816$, and $\mathrm{CFI}=0.868)$. The second model had better fit to the data than model $1(\chi 2(64, N=309)=186.27, p<.001, \mathrm{CMIN} / \mathrm{DF}=2.911, \mathrm{RMSEA}=0.079$, IFI $=$ 0.971 , TLI $=0.959$, and CFI $=0.971$ ), and all regression weights in the model were significant at $p<.001$. The correlation between the two latent teacher support variables was .828 . Hence, the results from the confirmatory factor analyses support the conceptualization of two separate but strongly correlated teacher support constructs.

We also tested a measurement model that included the motivational and emotional constructs by means of 
confirmatory factor analysis. The model defined four correlated primary factors with corresponding items (Figure 2). None of the error variances in the model were allowed to correlate. The model had good fit to the data $\left(\chi^{2}(129, N=309)=237.79, p<.001, \mathrm{CMIN} / \mathrm{DF}=1.843, \mathrm{RMSEA}=0.052, \mathrm{IFI}=0.972, \mathrm{TLI}=0.963\right.$, and $\mathrm{CFI}=0.972$ ), and all regression weights in the model were significant at $p<.001$. The correlations between the variables were moderate (see Figure 2). Supporting the zero-order correlations (see Table 1), the confirmatory factor analysis also revealed a non-significant correlation between math anxiety and effort. The result supports the conceptualization of four separate but moderately correlated constructs.

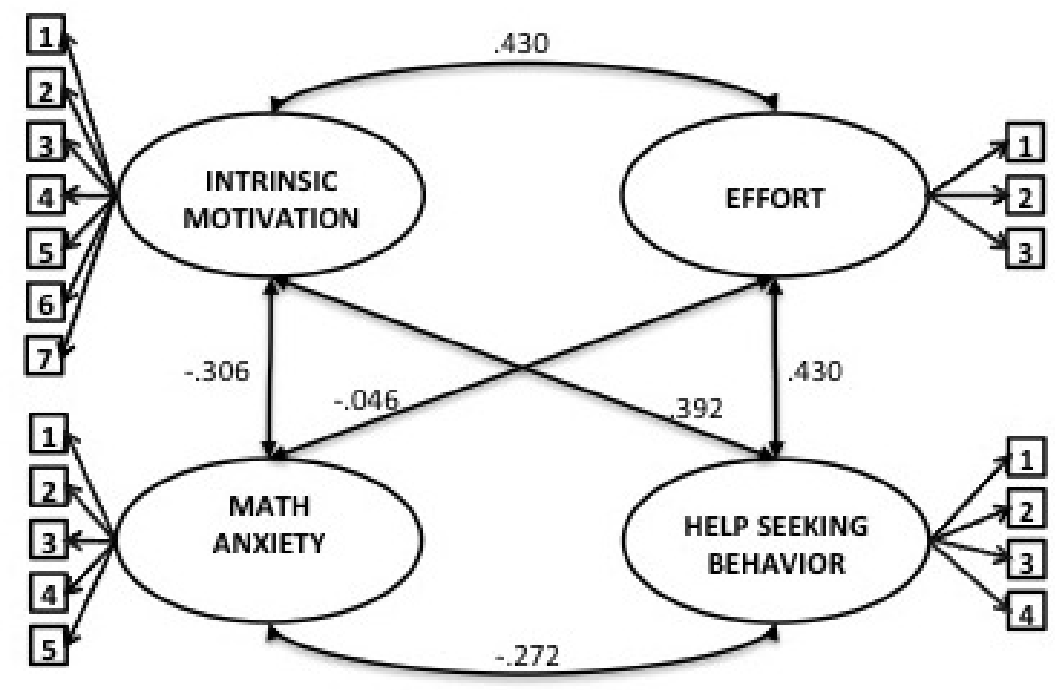

Figure 2. Measurement model of math anxiety, intrinsic motivation, effort, and help-seeking behavior

\subsection{Relations between Teacher Support and the Motivational and Emotional Constructs}

The relations between the variables were further investigated by means of structural equation modeling. We first tested the theoretical model displayed in Figure 1. The model (referred to as Model 1) defined emotional and instrumental support as exogenous variables. These variables were expected to be negatively related to math anxiety. Moreover, they were expected to be positively related to intrinsic motivation, effort, and help-seeking behavior, both directly and indirectly through math anxiety. In the model specification, none of the error variances were allowed to correlate. The model had acceptable fit to the data $(\chi 2(420, N=309)=807.33, p$ $<.001, \mathrm{CMIN} / \mathrm{DF}=2.922, \mathrm{RMSEA}=0.055, \mathrm{IFI}=0.954, \mathrm{TLI}=0.945$, and CFI $=0.954)$. Estimates of both unstandardized and standardized regression weights for all of the variables and the squared multiple correlations are presented in Table 2. Math anxiety was not significantly predicted by either emotional or instrumental support. Instrumental support predicted intrinsic motivation, effort, and help-seeking behavior positively and directly. It was particularly strongly related to intrinsic motivation, moderately related to help-seeking behavior, and weakly related to effort (standardized regression coefficients $=.491, .343$, and .170 , respectively). However, instrumental support was also indirectly related to effort (indirect effect $=.196$ ) and help-seeking behavior (indirect effect $=.132$ ). The indirect relations were mediated by intrinsic motivation. By contrast, emotional support was not significantly related to any of the motivational constructs. 
Table 2. Summary of SEM analysis of Model 1 including both emotional and instrumental support

\begin{tabular}{|c|c|c|c|c|}
\hline Latent variable & $\begin{array}{c}\text { Unstandardized } \\
\text { regression weights }\end{array}$ & $\begin{array}{c}\text { Standardized } \\
\text { regression weights }\end{array}$ & SE & $\mathrm{R}^{2}$ \\
\hline Math anxiety & & & & .019 \\
\hline Instrumental support & -.104 & -.093 & .133 & \\
\hline Emotional support & -.061 & -.049 & .151 & \\
\hline Intrinsic motivation & & & & .246 \\
\hline Instrumental support & $.664 * * *$ & .491 & .141 & \\
\hline Emotional support & -.191 & -.126 & .159 & \\
\hline Math anxiety & $-.311 * * *$ & -.256 & .068 & \\
\hline Effort & & & & .210 \\
\hline Instrumental support & .145 & .170 & .098 & \\
\hline Emotional support & -.031 & -.033 & .106 & \\
\hline Math anxiety & .068 & .089 & .047 & \\
\hline Intrinsic motivation & $.251 * * *$ & .396 & .045 & \\
\hline Help-seeking behavior & & & & .245 \\
\hline Instrumental support & $.348^{* *}$ & .343 & .011 & \\
\hline Emotional support & -.090 & -.079 & .119 & \\
\hline Math anxiety & $-.148 * *$ & -.162 & .053 & \\
\hline Intrinsic motivation & $.170 * * *$ & .227 & .046 & \\
\hline
\end{tabular}

Note: ${ }^{*} \mathrm{p}<.05,{ }^{* *} \mathrm{p}<.01,{ }^{* * *} \mathrm{p}<.001$

Because of a possible collinearity problem we also tested relations with emotional and instrumental support in separate analyses. In these analyses, gender and graded level were included as the exogenous variables. The first analysis, referred to as Model 2, included instrumental, but not emotional, support (Figure 3). None of the error variances were correlated. Initial analysis revealed that some of the regression weights between the latent variables were not significant at $\mathrm{p}<.05$. The non-significant regression weights are removed from Figure 3 . The final model had acceptable fit to the data $\left(\chi^{2}(311, N=309)=623.92, p<.001, \mathrm{CMIN} / \mathrm{DF}=2.006\right.$, RMSEA $=$ $0.057, \mathrm{IFI}=0.953$, TLI $=0.943$, and $\mathrm{CFI}=0.953)$. 


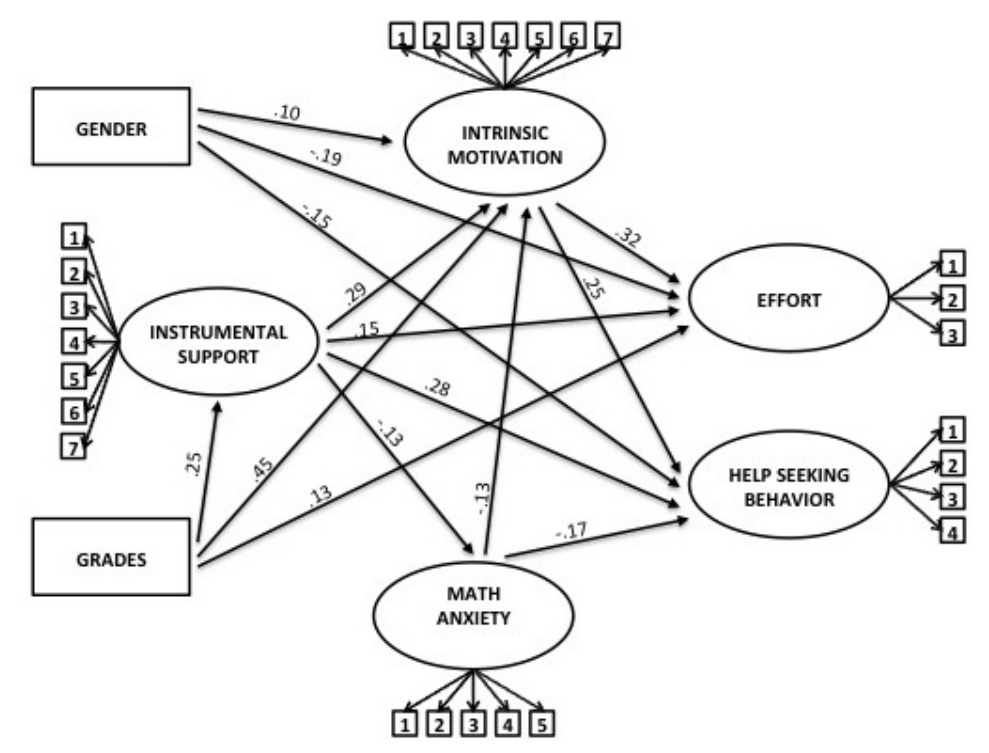

Figure 3. Structural model of relations between the latent constructs in Model 2 (instrumental support)

Figure 3 shows that instrumental support was negatively directly related to math anxiety and positively and directly related to intrinsic motivation, effort, and help-seeking behavior. In addition, instrumental support was indirectly related to intrinsic motivation through math anxiety and to effort through intrinsic motivation. Moreover, instrumental support was also indirectly related to help seeking behavior through both math anxiety and intrinsic motivation. Gender was significantly, but weakly, related to the motivational constructs. Male students showed higher intrinsic motivation for mathematics than female students, whereas female students showed higher effort and help-seeking behavior. Furthermore, grades were positively related to perceptions of instrumental support, intrinsic motivation for working with mathematics, and effort.

Figure 4 shows the result of the model that included emotional support (referred to as Model 3). Non-significant regression weights are removed from Figure 4 . The model had acceptable fit to the data $\left(\chi^{2}(287, N=309)=\right.$ $562.06, p<.001, \mathrm{CMIN} / \mathrm{DF}=1.958, \mathrm{RMSEA}=0.056, \mathrm{IFI}=0.952, \mathrm{TLI}=0.941$, and $\mathrm{CFI}=0.952)$. Figure 4 reveals that when analyzed separately, emotional support was associated with higher intrinsic motivation and help-seeking behavior. However, emotional support was not significantly and directly related to math anxiety or to effort. 


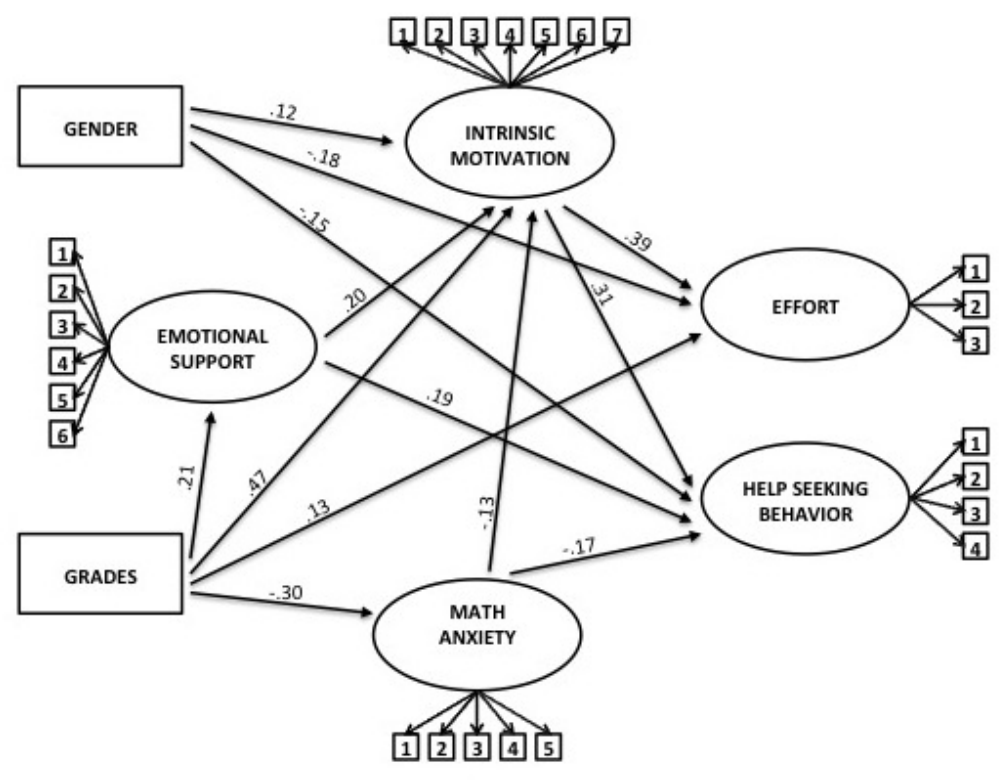

Figure 4. Structural model of relations between the latent constructs in Model 3 (emotional support)

\section{Discussion}

One purpose of the present study was to test the factor structure of items designed to measure two dimensions of teacher support, emotional support and instrumental support. Theoretically, emotional and instrumental supports represent different constructs. Emotional support was measured with items that assessed an individual student's perception of the math teacher as warm, friendly, and caring. By contrast, instrumental support was measured by items that evaluated the perception of whether the math teacher was helping the student understand and solve math problems and providing adequate guidance for working with mathematics when it was needed. Confirmatory factor analysis supported the conceptualization of emotional and instrumental support as separate but correlated constructs, and an alternative model that specified one single or general teacher support construct did not fit the data well. However, the two measures of teacher support were very strongly correlated. The correlation between the two latent constructs was .828 .

There are several possible interpretations of the strong correlation between emotional and instrumental support. One interpretation is that the mathematics teachers who care the most for the individual students tend to provide both emotional and instrumental support. We may speculate that these teachers care both for the individual student's general well-being and for the student's progress in mathematics. This possible interpretation of the strong correlation between emotional and instrumental support represents an explanation in terms of teacher characteristics. An alternative explanation in terms of student perception is that the teachers who provide adequate instrumental support are also perceived as emotionally supportive by the students. By helping the students understand the mathematics, solve mathematics problems, and develop mathematics skills, the teachers help the students make mastery experiences. This may lead the students to perceive the teachers as warm, friendly, and caring, which characterizes emotional support. We believe that the strong correlation between instrumental and emotional support can be explained by both teacher characteristics and that instrumental support is also perceived as emotional by the students.

Another alternative explanation may be that students perceive emotional support as instrumental support. We believe that this explanation is less plausible. For students who struggle with mathematics, emotional support alone may not improve their mathematics skills and understanding and may not increase the students' mastery experiences. In the absence of adequate instrumental support, these students may interpret emotional support as an acceptance of lack of effort and as a signal that the teachers have low expectations of their achievement (E. Skaalvik \& S. Skaalvik, 2013).

The testing of the SEM model that included both emotional and instrumental support (see Table 2) showed that emotional support was not significantly related to any of the emotional and motivational constructs (math anxiety, intrinsic motivation, effort and help-seeking behavior). By contrast, instrumental support was strongly 
associated with intrinsic motivation and moderately associated with help-seeking behavior. A possible reason is that when the shared variance is controlled for, instrumental support is the critical variable predicting math motivation and anxiety.

Another possible interpretation may be that the strong correlation between emotional and instrumental support may have created a multicollinearity problem. We therefore analyzed models that included either emotional or instrumental support separately (Figures 3 and 4). These analyses showed that both emotional and instrumental supports were significantly related to intrinsic motivation and help-seeking behavior. However, instrumental support was more strongly related to these constructs than was emotional support. Moreover, instrumental support was directly and negatively related to anxiety and directly and positively related to effort, whereas emotional support was not directly related to these constructs. These analyses support the interpretation that when the shared variance is controlled for, instrumental support is the critical variable predicting math motivation and anxiety.

The separate analyses of emotional and instrumental support revealed that both emotional and instrumental support were predictive of help-seeking behavior. Nevertheless, instrumental support was the strongest predictor. This is a particularly interesting result because several explanations of why many students avoid help-seeking have been proposed. Several researchers suggest that students may avoid help-seeking because it is perceived as an embarrassing situation, that students asking for help may be afraid of looking stupid and that it represents a threat to students' self-esteem (Fisher, Nadler, \& Whitcheralagna, 1982; Karabenick \& Knapp, 1991; Newman, 1998). In support of this notion, S. Skaalvik and E. Skaalvik (2005) found that the impact of mathematics self-concept and performance orientation on help-seeking behavior was mediated by the perception of help-seeking as threatening. A reasonable assumption would therefore be that teachers who provide emotional support would reduce such threat to self-esteem and that this would lead to an increase in help-seeking behavior. However, in the present study, instrumental support was the stronger predictor of help-seeking behavior. This may indicate that help-seeking behavior requires that students believe that help-seeking will result in adequate help to understand the schoolwork and that they expect such instrumental support to help improve their performance. Thus, though it is important that teachers are warm and friendly it has to be accompanied by instrumental support.

As could be expected, students' grades or level of performance in mathematics were positively related to intrinsic motivation and effort. Directly or indirectly, grades (or level of performance) were also negatively related to math anxiety. More interestingly, grades or level of performance was positively related to both emotional and instrumental support. This shows a tendency that the highest-achieving students perceive the teachers as most supportive. This is an important finding that should be tested in future research. In addition, future research should explore reasons for these differences in the perception of teacher support. We can only speculate about possible reasons. One reasonable assumption is that the lowest-achieving students receive the most attention and individual support from the teacher. If this assumption holds true, the findings in this study indicate that the extra attention does not lead to a stronger feeling of receiving emotional or instrumental support. An alternative explanation might be that the highest-achieving students receive the most positive or affirmative feedback from the teacher. Such affirmative feedback might be perceived both as emotional and instrumental support. A third possible explanation is that high-achieving students receive more autonomy support and trust from the teacher. We expect that such trust and autonomy support increases the students' feeling of receiving both emotional and instrumental support. However, these possible interpretations are merely speculations and must be studied in future research. Such studies have both theoretical and practical interest because teacher support is predictive of student motivation and emotion.

A practical implication of this study is that emotional support should be accompanied by instrumental support. As noted above, in the absence of instrumental support, a student may perceive emotional support as a sign that the teacher holds low expectations of the student's improvement and performance. This may be particularly true for low-achieving students. Teacher support should include both emotional and instrumental support. As noted by E. Skaalvik and S. Skaalvik (2013), it is also important that teacher support includes encouragement of effort and a focus on improvement.

This study has several limitations. The study was designed as a cross-sectional survey. Thus, the regression coefficients merely reveal relations between the constructs when all of the constructs in the SEM model are controlled for. Of note, the data do not support interpretations of the results in causal terms, even though such interpretations are based on theoretical analyses. Longitudinal studies of the same constructs are needed. Moreover, in this study, the measures of emotional and instrumental support represent students' perceptions of teacher support. In future studies, such measures should be combined with observation of teacher behavior. The 
present study is limited to middle grade students and their perception of teacher support in mathematics. More research is needed to explore students' perception of teacher support at other grade levels and in other school subjects. Finally, the concepts investigated in this study do not operate in isolation from other determinants of students' motivational and emotional responses, for instance, classroom goal structure, students' goals, and school grading system. In future research, such constructs should be explored in relation to those included in the current study.

\section{References}

Ahmed, W., Minnaert, A., van der Werf, G., \& Kuyper, H. (2010). Perceived Social Support and Early Adolescents' Achievement: The Mediational Roles of Motivational Beliefs and Emotions. Journal of Youth and Adolescence, 39(1), 36-46. http://dx.doi.org/10.1007/s10964-008-9367-7

Bandura, A. (1977). Self-Efficacy-Toward a unifying theory of behavioral change. Psychological Review, 84(2), 191-215. http://dx.doi.org/10.1037/0033-295X.84.2.191

Bandura, A. (1997). Self-efficacy: the exercise of control. New York: Freeman.

Baumeister, R. F., \& Leary, M. R. (1995). The Need to Belong-Desire for Interpersonal Attachments as a Fundamental Human-Motivation. Psychological Bulletin, 117(3), 497-529. http://dx.doi.org/10.1037/0033-2909.117.3.497

Bezzina, F. H. (2010). Investigating gender differences in mathematics performance and in self-regulated learning: An empirical study from malta. Equality, Diversity and Inclusion: An International Journal, 29, 669-693. http://dx.doi.org/10.1108/02610151011074407

Byrne, B. M. (2010). Structural equation modeling with AMOS: Basic concepts, applications, and programming. New York: Routledge.

Cecchini, J., González, C., Carmona, Á., Arruza, J., Escartí, A., \& Balagué, G. (2001). The influence of the physical education teacher on intrinsic motivation, self-confidence, anxiety, and pre- and post-competition mood states. European Journal of Sport Science, 1(4), 1-11. http://dx.doi.org/10.1080/17461390100071407

Crosnoe, R., Johnson, M. K., \& Elder, G. H. (2004). School size and the interpersonal side of education: An examination of race/ethnicity and organizational context. Social Science Quarterly, 85(5), 1259-1274. http://dx.doi.org/10.1111/j.0038-4941.2004.00275.x

Cutrona, C. E., \& Suhr, J. A. (1994). Social support communication in the context of marriage: An analysis of couples' supportive interactions. In B. R. Burleson, T. L. Albrecht, \& I. G. Sarason (Eds.), Communication of social support: Messages, interactions, relationships, and community (pp. 113-135). Thousand Oaks, CA: Sage.

Danielsen, A. G., Wiium, N., Wilhelmsen, B. U., \& Wold, B. (2010). Perceived support provided by teachers and classmates and students' self-reported academic initiative. Journal of School Psychology, 48(3), 247-267. http://dx.doi.org/10.1016/j.jsp.2010.02.002

De Wit, D. J., Karioja, K., Rye, B. J., \& Shain, M. (2011). Perceptions of Declining Classmate and Teacher Support Following the Transition to High School: Potential Correlates of Increasing Student Mental Health Difficulties. Psychology in the Schools, 48(6), 556-572. http://dx.doi.org/10.1002/pits.20576

Deci, E. L., \& Ryan, R. M. (1985). The General Causality Orientations Scale - Self-Determination in Personality. Journal of Research in Personality, 19(2), 109-134. http://dx.doi.org/10.1016/0092-6566(85)90023-6

Deci, E. L., \& Ryan, R. M. (2000). The "what" and "why" of goal pursuits: Human needs and the self-determination of behavior. Psychological Inquiry, $11(4), \quad 227-268$. http://dx.doi.org/10.1207/S15327965PLI1104_01

Fisher, J. D., Nadler, A., \& Whitcheralagna, S. (1982). Recipient Reactions to Aid. Psychological Bulletin, 91(1), 27-54. http://dx.doi.org/10.1037/0033-2909.91.1.27

Furrer, C., \& Skinner, E. (2003). Sense of relatedness as a factor in children's academic engagement and performance. Journal of Educational Psychology, $148-162$. http://dx.doi.org/10.1037/0022-0663.95.1.148

Goldstein, L. S. (1999). The relational zone: The role of caring relationships in the co-construction of mind. American Educational Research Journal, 36(3), 647-673. http://dx.doi.org/10.3102/00028312036003647

Goodenow, C., \& Grady, K. E. (1993). The Relationship of School Belonging and Friends Values to Academic 
Motivation among Urban Adolescent Students. Journal of Experimental Education, 62(1), 60-71. http://dx.doi.org/10.1080/00220973.1993.9943831

Hamre, B. K., \& Pianta, R. C. (2001). Early teacher-child relationships and the trajectory of children's school outcomes through eighth grade. Child Development, $625-638$. http://dx.doi.org/10.1111/1467-8624.00301

House, J. (1981). Work stress and social support. Reading, MA: Addison-Weslay.

Hu, L.-T., \& Bentler, P. M. (1999). Cutoff criteria for fit indexes in covariance structure analysis: Conventional criteria versus new alternatives. Structural Equation Modeling, 6(1), 1-55. http://dx.doi.org/10.1080/10705519909540118

Jang, H., Reeve, J., \& Deci, E. L. (2010). Engaging Students in Learning Activities: It Is Not Autonomy Support or Structure but Autonomy Support and Structure. Journal of Educational Psychology, 102(3), 588-600. http://dx.doi.org/10.1037/a0019682

Karabenick, S. A. (2004). Perceived achievement goal structure and college student help seeking. Journal of Educational Psychology, 96(3), 569-581. http://dx.doi.org/10.1037/0022-0663.96.3.569

Karabenick, S. A., \& Knapp, J. R. (1991). Relationship of Academic Help Seeking to the Use of Learning-Strategies and Other Instrumental Achievement Behavior in College-Students. Journal of Educational Psychology, 83(2), 221-230. http://dx.doi.org/10.1037/0022-0663.83.2.221

Karabenick, S. A., \& Sharma, R. (1994). Perceived Teacher Support of Student Questioning in the College Classroom-Its Relation to Student Characteristics and Role in the Classroom Questioning Process. Journal of Educational Psychology, 86(1), 90-103. http://dx.doi.org/10.1037/0022-0663.86.1.90

Katz, I., Kaplan, A., \& Gueta, G. (2010). Students' Needs, Teachers' Support, and Motivation for Doing Homework: A Cross-Sectional Study. Journal of Experimental Education, 78(2), $246-267$. http://dx.doi.org/10.1080/00220970903292868

Langford, C. P. H., Bowsher, J., Maloney, J. P., \& Lillis, P. P. (1997). Social support: A conceptual analysis. Journal of Advanced Nursing, 25(1), 95-100. http://dx.doi.org/10.1046/j.1365-2648.1997.1997025095.x

Lapointe, J. M., Legault, F., \& Batiste, S. J. (2005). Teacher interpersonal behavior and adolescents' motivation in mathematics: A comparison of learning disabled, average, and talented students. International Journal of Educational Research, 43(1-2), 39-54. http://dx.doi.org/10.1016/j.ijer.2006.03.005

Malecki, C. K., \& Demaray, M. K. (2003). What Type of Support Do They Need? Investigating Student Adjustment as Related to Emotional, Informational, Appraisal, and Instrumental Support. School Psychology Quarterly, 18(3), 231-252. http://dx.doi.org/10.1521/scpq.18.3.231.22576

Marchand, G., \& Skinner, E. A. (2007). Motivational dynamics of children's academic help-seeking and $\begin{array}{lllll}\text { concealment. } \quad \text { Journal } & \text { Ed }\end{array}$ http://dx.doi.org/10.1037/0022-0663.99.1.65

Marsh, H. W. (1990). SDQ II: Manual \& Research Monograph. New York: The Psychological Corporation, Harcourt Brace Jonanovich.

Martin, A. J., \& Dowson, M. (2009). Interpersonal Relationships, Motivation, Engagement, and Achievement: Yields for Theory, Current Issues, and Educational Practice. Review of Educational Research, 79(1), 327-365. http://dx.doi.org/10.3102/0034654308325583

Metallidou, P., \& Vlachou, A. (2007). Motivational beliefs, cognitive engagement, and achievement in language and mathematics in elementary school children. International Journal of Psychology, 42(1), 2-15. http://dx.doi.org/10.1080/00207590500411179

Myers, S. A., Edwards, C., Wahl, S. T., \& Martin, M. M. (2007). The Relationship Between Perceived Instructor Aggressive Communication and College Student Involvement. Communication Education, 56(4), 495-508. http://dx.doi.org/10.1080/03634520701466398

Nelson-LeGall, S., \& Resnick, L. (1998). Help-seeking, achievement motivation and the social practice of intelligence in school. In S. A. Karabenick (Ed.), Strategic help-seeking. Implications for learning and teaching (pp. 13-37). Mahwah, NJ: Lawrence Erlbaum Ass.

Newman, R. S. (1998). Adaptive help-seeking: A role of social interaction in self-regulated learning. In S. A. Karabenick (Ed.), Strategic help-seeking. Implications for learning and teaching (pp. 13-37). Mahwah, NJ: 
Lawrence Erlbaum Ass.

Newman, R. S. (2000). Social Influences on the Development of Children's Adaptive Help Seeking: The Role of Parents, Teachers, and Peers. Developmental Review, 20(3), 350-404. http://dx.doi.org/10.1006/drev.1999.0502

Newman, R. S. (2002). How Self-Regulated Learners Cope with Academic Difficulty: The Role of Adaptive Help Seeking. Theory Into Practice, 41(2), 132-138. http://dx.doi.org/10.1207/s15430421tip4102_10

Newman, R. S. (2008). The motivational role of adaptive help seeking in self-regulated learning. In D. H. Schunk, \& B. J. Zimmerman (Eds.), Motivation and self-regulated learning: Theory, research, and applications (pp. 15-337). New York, NY: Lawrence Erlbaum.

Newman, R. S., \& Goldin, L. (1990). Childrens Reluctance to Seek Help with Schoolwork. Journal of Educational Psychology, 82(1), 92-100. http://dx.doi.org/10.1037/0022-0663.82.1.92

Newman, R. S., \& Schwager, M. T. (1993). Students Perceptions of the Teacher and Classmates in Relation to Reported Help-Seeking in Math Class. Elementary School Journal, 94(1), 3-17. http://dx.doi.org/10.1086/461747

Niehaus, K., Rudasill, K. M., \& Rakes, C. R. (2012). A longitudinal study of school connectedness and academic outcomes across sixth grade. Journal of School Psychology, 50(4), 443-460. http://dx.doi.org/10.1016/j.jsp.2012.03.002

Patrick, H., Kaplan, A., \& Ryan, A. M. (2011). Positive Classroom Motivational Environments: Convergence Between Mastery Goal Structure and Classroom Social Climate. Journal of Educational Psychology, 103(2), 367-382. http://dx.doi.org/10.1037/A0023311

Patrick, H., Ryan, A. M., \& Kaplan, A. (2007). Early adolescents' perceptions of the classroom social environment, motivational beliefs, and engagement. Journal of Educational Psychology, 99(1), 83-98. http://dx.doi.org/10.1037/0022-0663.99.1.83

Pianta, R. C., Hamre, B., \& Stuhlman, M. (2003). Relationships Between Teachers and Children Handbook of Psychology. John Wiley \& Sons, Inc.

Pintrich, P. R., \& Schunk, D. H. (2008). Motivation in education: Theory, research, and applications (2nd ed.). Upper Saddle River, N.J.: Merrill Prentice Hall.

Roeser, R. W., Midgley, C., \& Urdan, T. C. (1996). Perceptions of the school psychological environment and early adolescents' psychological and behavioral functioning in school: The mediating role of goals and belonging. Journal of Educational Psychology, $48(3), \quad 408-422$. http://dx.doi.org/10.1037/0022-0663.88.3.408

Ryan, A. M., \& Patrick, H. (2001). The classroom social environment and changes in adolescents' motivation and engagement during middle school. American Educational Research Journal, 38(2), 437-460. http://dx.doi.org/10.3102/00028312038002437

Ryan, A. M., Gheen, M. H., \& Midgley, C. (1998). Why Do Some Students Avoid Asking for Help? An Examination of the Interplay among Students' Academic Efficacy, Teachers' Social-Emotional Role, and the Classroom Goal Structure. Journal of Educational Psychology, 90(3), 528-535. http://dx.doi.org/10.1037/0022-0663.90.3.528

Ryan, R. M., \& Deci, E. L. (2000). Intrinsic and Extrinsic Motivations: Classic Definitions and New Directions. Contemporary Educational Psychology, 25(1), 54-67. http://dx.doi.org/10.1006/ceps.1999.1020

Ryan, R. M., \& Deci, E. L. (2006). Self-Regulation and the Problem of Human Autonomy: Does Psychology Need Choice, Self-Determination, and Will? Journal of Personality, 74(6), 1557-1586. http://dx.doi.org/10.1111/j.1467-6494.2006.00420.x

Sakiz, G. (2012). Perceived instructor affective support in relation to academic emotions and motivation in college. Educational Psychology, 32(1), 63-79. http://dx.doi.org/1080/01443410.2011.625611

Sakiz, G., Pape, S. J., \& Hoy, A. W. (2012). Does perceived teacher affective support matter for middle school students in mathematics classrooms? Journal of School Psychology, 50(2), 235-255. http://dx.doi.org/10.1016/j.jsp.2011.10.005

Searcy, E., \& Eisenberg, N. (1992). Defensiveness in Response to Aid from a Sibling. Journal of Personality and Social Psychology, 62(3), 422-433. http://dx.doi.org/10.1037/0022-3514.62.3.422 
Semmer, N. K., Elfering, A., Jacobshagen, N., Perrot, T., Beehr, T. A., \& Boos, N. (2008). The emotional meaning of instrumental social support. International Journal of Stress Management, 15(3), 235-251. http://dx.doi.org/10.1037/1072-5245.15.3.235

Skaalvik, E. M., \& Skaalvik, S. (2013). School goal structure: Associations with students' perceptions of their teachers as emotionally supportive, academic self-concept, instrinsic motivation, effort, and help seeking behavior. International Journal of Educational Research, 61, 5-14. http://dx.doi.org/10.1016/j.ijer.2013.03.007

Skaalvik, S., \& Skaalvik, E. M. (2004). Gender differences in Math and verbal self-concept, performance $\begin{array}{lllll}\text { expectations, and } & \text { 241-252. }\end{array}$ http://dx.doi.org/10.1023/B:SERS.0000015555.40976.e6

Skaalvik, S., \& Skaalvik, E. M. (2005). Self-Concept, Motivational Orientation, and Help-Seeking Behavior in Mathematics: A Study of Adults Returning to High School. Social Psychology of Education, 8(3), 285-302. http://dx.doi.org/10.1007/s11218-005-3276-3

Spielberger, C. D. (1972). Anxiety: Current trends in theory and research. New York: Academic Press.

Spielberger, C. D. (1979). Understanding stress and anxiety. London: Harper \& Row.

Suldo, S. M., Friedrich, A. A., White, T., Farmer, J., Minch, D., \& Michalowski, J. (2009). Teacher Support and Adolescents' Subjective Well-Being: A Mixed-Methods Investigation. School Psychology Review, 38(1), 67-85.

Tabachnick, B. G., \& Fidell, L. S. (2007). Using multivariate statistics. Boston: Pearson/Allyn and Bacon.

Wentzel, K. R. (1994). Relations of social goal pursuit to social acceptance, classroom behavior, and perceived $\begin{array}{lllll}\text { social support. Journal of Educational Psychology, } & \text { 86(2), }\end{array}$ http://dx.doi.org/10.1037/0022-0663.86.2.173

Wentzel, K. R. (1998). Social relationships and motivation in middle school: The role of parents, teachers, and peers. Journal of Educational Psychology, 90(2), 202-209. http://dx.doi.org/10.1037//0022-0663.90.2.202

Wentzel, K. R. (1999). Social-motivational processes and interpersonal relationships: Implications for understanding motivation at school. Journal of Educational Psychology, 91(1), 76-97. http://dx.doi.org/10.1037/0022-0663.91.1.76

Wentzel, K. R., Battle, A., Russell, S. L., \& Looney, L. B. (2010). Social supports from teachers and peers as predictors of academic and social motivation. Contemporary Educational Psychology, 35(3), 193-202. http://dx.doi.org/10.1016/j.cedpsych.2010.03.002

Yildirim, S. (2012). Teacher Support, Motivation, Learning Strategy Use, and Achievement: A Multilevel Mediation Model. Journal of Experimental Education, 80(2), 150-172. http://dx.doi.org/10.1080/00220973.2011.596855

\section{Appendix}

The items were developed and administered in Norwegian. The items represent translations into English.

Emotional support

I feel that my math teacher cares about me.

I feel that my math teacher is friendly.

My math teacher makes me feel safe.

My math teacher respects me.

My math teacher is friendly.

My math teacher wants what is best for me.

Instrumental support

When there is something I do not understand in mathematics, my math teacher explains it well for me.

When I have problems with math, I get good help and guidance from my math teacher.

My math teacher helps me so that I understand the math problems. 
My teacher provides good guidance.

My math teacher is always available when I need assistance.

My teacher is good at explaining challenging math problems.

Intrinsic motivation

I like mathematics.

Working with mathematics is fun.

I enjoy working with mathematics.

I look forward to classes in mathematics.

I would like to have additional lessons in mathematics.

I would like to skip math classes.

Math anxiety

I am tense in math lessons.

I am nervous in math lessons.

I am afraid to make a fool of myself in math lessons.

I get heartbeats if I am asked a question in math lessons.

When I am working with math I get so nervous that I can't think straight.

\section{Help-seeking behavior}

If there is something I do not understand in math, I ask the teacher for help.

If I am working on a math problem that I am not able to solve, I ask the teacher for advice.

In mathematics lessons, I do not ask for help even if I do not understand the problem I am working with.

If I need help in mathematics I ask for it.

Effort

I always do my best when I am working with mathematics.

I always do my homework in mathematics.

I often rush through my work in mathematics.

\section{Copyrights}

Copyright for this article is retained by the author(s), with first publication rights granted to the journal.

This is an open-access article distributed under the terms and conditions of the Creative Commons Attribution license (http://creativecommons.org/licenses/by/3.0/). 